\title{
BASE COMUM NACIONAL OU BASE NACIONAL COMUM PARA A FORMAÇÃO INICIAL DE PROFESSORES DA EDUCAÇÃO BÁSICA: A QUEM INTERESSA A INVERSÃO DA NOMENCLATURA?
}

\begin{abstract}
National common base or common national base for initial training of basic education teachers: who is the inversion of nomenclature interested in?
\end{abstract}

Base común nacional o base nacional común para la formación inicial de profesores de educación básica: ¿en quién está interesado la inversión de la nomenclatura?

Yuna Lélis Beleza Lopes* Noeli Prestes Padilha Rivas**

https://doi.org/10.38117/2675-181X.formov2021.v3i1n5.71-91.

\section{Resumo}

O cenário presente das políticas de formação docente está relacionado a projetos formativos que expressam tensões, disputas e interesses em jogo para a sua implementação. O tema decorre de estudos de pós-graduação em educação e no contexto do grupo de estudos e pesquisas em uma universidade pública paulista e tem como objetivo analisar as atuais normativas nacionais no campo da formação de professores, principalmente na área da Pedagogia. Trata-se de pesquisa qualitativa de cunho exploratório com utilização de análise documental. Os resultados apontam que essas legislações desconsideram o conhecimento historicamente produzido nesse campo e encaminham os cursos de licenciatura ao esvaziamento da formação crítica e científica, à dicotomia teoria e prática, à dissociação entre pesquisa e ensino, ao alinhamento da formação inicial dos professores com a Base Nacional Comum Curricular (BNCC), ao reducionismo da formação teórica à prática pela prática, dentre outras implicações.

Palavras-chave: Curso de Pedagogia; Formação de Professores; Políticas Educacionais; Diretrizes Curriculares; Base Comum Nacional. 


\begin{abstract}
The current scenario of teacher education policies is related to training projects which express tensions, disputes and interests at stake for their implementation. The theme stems from postgraduate studies in education and in the context of the group of studies and research at a public university in São Paulo and aims to analyze the current national regulations in the field of teacher education, mainly Pedagogy. It is an exploratory qualitative research using documentary analysis. The results show that these laws disregard the knowledge historically produced by the referred field and lead undergraduate courses to the emptying of critical and scientific training, to the dichotomy between theory and practice, to the dissociation between research and teaching, to the alignment of the initial training of teachers with National Common Curricular Base (BNCC), the reduction of theoretical training to practice by practice, among other determinations.
\end{abstract}

Keywords: Pedagogy Course; Teacher training; Educational Policies; Curricular Guidelines; National Common Base.

\title{
Resumen
}

El escenario actual de las políticas de formación docente está relacionado con proyectos de formación que expresan tensiones, disputas e intereses en juego para su implementación. El tema surge de los estudios de posgrado en educación y en el contexto del grupo de estudios e investigación de una universidad pública de São Paulo y tiene como objetivo analizar la normativa nacional vigente en el campo de la formación docente, principalmente Pedagogía. Es una investigación cualitativa exploratoria que utiliza análisis documental. Los resultados muestran que estas leyes desconocen el conocimiento históricamente producido por el campo referido y conducen a los cursos de pregrado al vaciamiento de la formación crítica y científica, a la dicotomía entre teoría y práctica, a la disociación entre investigación y docencia, a la alineación de la formación inicial del profesorado con Base Curricular Común Nacional (BNCC), la reducción de la formación teórica a práctica por práctica, entre otras determinaciones.

Palabras clave: Curso de Pedagogía; Formación de profesores; Políticas educativas; Pautas curriculares; Base Común Nacional.

\section{Introdução}

O tema formação de professores, nas últimas décadas, tem sido recorrente, seja na discussão em torno de seu campo epistemológico, enquanto objeto de investigação (em estudos, pesquisas, cursos de pós-graduação), seja em debates concernentes à 
Base Comum Nacional ou Base Nacional Comum para formação inicial de professores da educação básica: A quem interessa a inversão de nomenclatura?

profissionalização (formação inicial e formação continuada) assim como na formulação de políticas públicas.

A temática suscita disputas, tensões e resistências, considerando o cenário vigente na sociedade principalmente no que tange à multiplicidade de processos heterogêneos, denominados de "nova racionalidade governamental" (DARDOT; LAVAL, 2016, p.3334), isto é, ao cruzamento de dimensões, conflitos e realidades que se manifestam não só no estudo do currículo, em suas determinações visíveis e invisíveis, mas também em sua constituição enquanto ferramenta de regulação das práticas pedagógicas (GIMENO SACRISTÁN, 2013; LOPES; MACEDO, 2011), e ainda ao processo histórico da escola, que provoca mudanças profundas na profissão docente e na formação de professores. É, portanto, na triangulação destes três espaços - profissionais, universitários e escolares que se encontram as potencialidades transformadoras da formação docente (NÓVOA, 2019).

A formação de professores para a Educação Básica ocorre nos Cursos de Licenciaturas (na esfera da graduação, nível superior). Desde a Lei de Diretrizes e Bases da Educação Nacional (LDBEN, no 9.394/1996), várias normativas legais têm sido criadas no âmbito da formação de professores, denominadas Diretrizes Curriculares Nacionais, Política Nacional de Formação, dentre outras. ${ }^{1}$ Em dezembro de 2019 foi aprovada no Conselho Nacional de Educação (CNE), pelo Conselho Pleno (CP), a Resolução CNE/CP $\mathrm{n}^{\circ}$ 2, a qual define as Diretrizes Curriculares Nacionais para a Formação Inicial de Professores para a Educação Básica e institui a Base Nacional Comum para a Formação Inicial de Professores da Educação Básica (BNC-Formação). Tal legislação tem sido alvo de discussões no ambiente acadêmico entre entidades e pesquisadores da área de formação de professores e políticas curriculares, tendo em vista seu contexto, texto e ajustamento às políticas neoliberais (ANPED, 2019; FREITAS, 2020, 2019; TAFFAREL, 2020).

Os pressupostos teóricos que norteiam esta discussão estão centrados principalmente na especificidade da Pedagogia enquanto ciência práxica, ou seja, “[...] atividade prática carregada de uma intenção (teoria) transformadora da realidade" (PIMENTA; PINTO; SEVERO, 2020, p. 6). Acrescenta-se, ainda, que no campo da formação de professores há princípios consolidados que fundamentam a Base Comum

\footnotetext{
${ }^{1}$ Diretrizes Curriculares de Formação de Professores (Resoluções CNE/CP no 1 e 2/2002); Diretrizes Curriculares Nacionais para a formação inicial em nível superior (cursos de licenciatura, cursos de formação pedagógica para graduados e cursos de segunda licenciatura) e para a formação continuada (Resolução CNE/CP nº 2/2015); Política Nacional de Formação dos Profissionais da Educação Básica (Decreto $\left.\mathrm{n}^{\circ} 8.752 / 2016\right)$.
} 
Nacional, sistematizada pela Associação Nacional pela Formação dos Profissionais da Educação (ANFOPE), ou seja, "uma concepção básica de formação do educador e a definição de um corpo de conhecimento fundamental" (ANFOPE, 2018, p. 10), balizadores que diferem significativamente do que é proposto pela inversão da nomenclatura (Base Nacional Comum, da BNC-Formação).

Este texto soma-se ao contexto de tensão no que concerne às políticas curriculares no âmbito da formação docente, na graduação, e pretende retomar as reflexões iniciais apresentadas no II Congresso Brasileiro de Pedagogia Universitária (II CBPU), ocorrido na Universidade Estadual Paulista "Júlio de Mesquita Filho" (UNESP, campus Rio Claro). À época, o trabalho foi escrito no decorrer da tramitação do Projeto da nova Resolução ( $3^{a}$ versão do Parecer CNE/MEC, datada em 18/09/2019), texto referência para orientar as Diretrizes Curriculares Nacionais para a Formação Inicial de Professores para a Educação Básica e Base Nacional Comum para a Formação Inicial de Professores da Educação Básica (BNC-Formação).

Deste modo, este trabalho tem como propósito dar enfoque à política de formação de professor, a partir do Parecer CNE/CP n ${ }^{\circ}$ 22/2019 e a decorrente Resolução CNE/CP $n^{\circ}$ 2/2019 (homologada em 20 de dezembro de 2019), a qual se insere no âmbito das atuais políticas curriculares, (im)posta nacionalmente. O presente artigo também está incorporado em linha de pesquisa no campo da formação de professores e currículo, do grupo de estudos de uma universidade pública do interior de São Paulo e se constitui em um recorte de tese de doutorado (em andamento).

Nesse sentido, torna-se necessária a discussão das atuais normativas atinentes à formação de professores, uma vez que estas impactam diretamente a organização curricular dos cursos de Licenciatura - especialmente a Pedagogia, em diversas dimensões -, por desconsiderarem o processo histórico do campo de formação de professores, baseado em estudos e pesquisas cujo fundamento é uma concepção omnilateral de formação humana. Entende-se que uma Resolução do CNE, homologada pelo Ministro da Educação, tem força de lei; mas que, entretanto, pode ser passível de movimentos de resistência ou de outros processos que possibilitem a participação de uma sociedade pautada por uma educação pública de qualidade socialmente referenciada, diferente do que ocorreu com a Resolução CNE/CP nº 2/2019.

Em consonância com Freitas (2019), considera-se que, dentre as razões que justificam um olhar cuidadoso e crítico à BNC-Formação e às competências profissionais que dela decorrem, destacam-se: I) o processo de desmonte e destruição da universidade pública e dos atuais cursos de licenciatura no que concerne à autonomia universitária, 
visto que o documento apresenta e reduz a formação inicial a competências gerais e específicas atreladas à Base Nacional Comum Curricular (BNCC); II) é um documento que provoca a retirada da autonomia docente; e III) deve-se responsabilizar o CNE e o Ministério da Educação (MEC) diante do quadro atual das licenciaturas, isso porque a maioria das vagas em cursos de licenciatura estão em instituições privadas de ensino. Ou seja, as normativas têm intencionalidade e reverberam nas ações desenvolvidas pelas Instituições de Ensino Superior (IES) e sistemas educativos.

$\mathrm{Na}$ organização do texto, as temáticas foram focalizadas em dimensões de construção, inter-relações, imbricações, destaques e ideias-chave. Num primeiro momento, evidencia-se o contexto de internacionalização das políticas educativas e curriculares e sua relação com a formação de professores. A seguir, debate-se acerca das decorrências dos atos normativos atuais oriundas do CNE e do MEC), no que diz respeito ao Parecer CNE/CP no 22 e à Resolução CNE/CP n 2 (ambos de 2019), ao estatuto epistemológico da Pedagogia e seu lugar como Ciência da Educação. A inversão da nomenclatura Base Nacional Comum (BNC), posta na atual legislação, e Base Comum Nacional (princípios e pressupostos da ANFOPE que incorporam a Resolução CNE/CP $n^{\circ} 2 / 2015$ ) representam diferentes matrizes teóricas que fundamentam a formação inicial de professores da educação básica. Por último, considera-se relevante que se desvele a que vieram tais proposições de revisão da Resolução de 2015, haja vista que as atuais legislações abarcam a concepção de formação inicial baseada no caráter técnicoinstrumental, evidenciando o estreitamento do currículo de formação, ao considerarem os futuros professores meros gestores/práticos da BNCC.

\section{Internacionalização das políticas educativas e agenda de formação de professores}

No século XXI acirram-se as assimetrias na educação em todos os níveis de ensino, principalmente na educação superior, com mudanças de paradigma na ciência, tecnologia, produção de conhecimento, influência de organismos supranacionais que reverberam no currículo, ensino, aprendizagem e profissionalidade docente. Estes processos estão engendrados num contexto de globalização, de natureza econômica, política e cultural (GIDDENS, 2007), com transformações no capitalismo oriundas do modelo neoliberal (DARDOT. LAVAL, 2016). Além disso, é possível afirmar que o "estado do mundo é globalizado, apoiando-se na crença de que o conhecimento é um 
valor econômico adicionado, na medida em que o ponto fulcral da competitividade residiria na economia do conhecimento" (PACHECO; SOUZA; MAIA, 2020, p. 385).

De acordo com Sousa Santos (2008, p.19), a "perda de prioridade na universidade pública nas políticas educacionais do Estado foi inicialmente, o resultado da perda geral de prioridade das políticas sociais (educação, saúde, previdência)", em razão do modelo de desenvolvimento econômico (neoliberalismo ou globalização neoliberal), que se impôs internacionalmente a partir da década de 1980. Desse processo, o autor anuncia três crises (hegemonia, legitimidade e institucional) que impactam a universidade em suas funções tradicionais, na hierarquização dos saberes especializados, nas exigências sociais e políticas que impõem contradição entre sua autonomia e responsabilidade social, bem como a submetem à pressão de critérios de eficácia e de produtividade de natureza empresarial. Nesse contexto, a produção e a socialização do conhecimento são constitutivas da formação humana e, nas universidades, assumem significativo papel, qual seja, responder com qualidade às exigências e necessidades da sociedade, ser uma universidade na perspectiva de instituição social.

Chauí (2003) adverte que "a universidade deixa de ser instituição social" para atender interesses políticos e econômicos necessários ao desenvolvimento do setor produtivo, do mercado. Na concepção de universidade organizacional, os valores e concepções que orientam a formação estão desvinculados e passam a se orientar pela lógica do desenvolvimento do mercado, das inovações científicas e tecnológicas, das mídias digitais (não que essas não sejam importantes e não façam parte do currículo; porém, o que se questiona é o como essas inovações consomem os espaços curriculares e o espaço público da formação do indivíduo).

Estes processos estão engendrados num contexto de globalização, de natureza econômica, política e cultural (GIDDENS, 2007), com transformações no capitalismo oriundas do modelo neoliberal (DARDOT. LAVAL, 2016). Além disso, é possível afirmar que o "estado do mundo é globalizado, apoiando-se na crença de que o conhecimento é um valor econômico adicionado, na medida em que o ponto fulcral da competitividade residiria na economia do conhecimento" (PACHECO; SOUZA; MAIA, 2020, p. 385).

Oliveira (2020), ao discutir a respeito da circulação e transferência de políticas educacionais e da profissão docente, destaca o papel dos organismos internacionais, representados principalmente pela Organização para a Cooperação e Desenvolvimento Econômico (OCDE). Argumenta a autora que os "organismos internacionais baseados em forte fundamentação com matriz na teoria do capital humano vêm definindo padrões 
Base Comum Nacional ou Base Nacional Comum para formação inicial de professores da educação básica: A quem interessa a inversão de nomenclatura?

para identificar, avaliar e determinar o que é a 'qualidade da educação' e a 'boa docência' utilizando [...] dispositivos" (p. 90) para influenciar a organização dos sistemas educacionais (em âmbito internacional) reforçando, assim, os vínculos entre produtividade, capital humano e políticas educacionais.

Ressalta ainda Oliveira (2020, p.81) que a "importância atribuída aos docentes na agenda da reforma educacional global é a justificativa para um dos mais importantes esforços da OCDE que teve início nesta década: as Cúpulas Internacionais sobre Profissão Docente (International Summit on the Teaching Profession)". As intencionalidades desses organismos são explicitadas em seus documentos como descritas no fragmento abaixo:

\begin{abstract}
Mas esperamos muito mais do que o que colocamos nas descrições de cargo dos professores. Também esperamos que os professores sejam apaixonados, compassivos e atenciosos; tornar o aprendizado central e incentivar o envolvimento e a responsabilidade dos alunos; para responder efetivamente a estudantes de diferentes necessidades, formações e idiomas; promover a tolerância e a coesão social; fornecer feedback e avaliações contínuas dos alunos; e garantir que os estudantes se sintam valorizados e incluídos e que o aprendizado seja colaborativo. E esperamos que os próprios professores colaborem e trabalhem em equipe e com outras escolas e pais, sejam capazes de estabelecer metas comuns e planejar e monitorar a consecução de metas. E há mais do que isso. As pessoas de sucesso geralmente tinham um professor que era um mentor e tinham um interesse real em suas vidas e aspirações, que os ajudaram a entender quem são, a descobrir suas paixões e como podem construir pontos fortes, professores que os ensinaram a amar aprender e desenvolver estratégias eficazes de aprendizagem e os ajudaram a descobrir como eles podem fazer a diferença no progresso social (OCDE, 2018, apud OLIVEIRA, 2020, p. 91-92).
\end{abstract}

O recorte que se faz neste artigo expõe a tensão que perpassa a Educação, de forma geral, no que tange às demandas da sociedade para a área da formação de professores, principalmente tratando-se da formação inicial de professores, bem como as atuais normativas construídas no âmbito do $\mathrm{CNE}$, as quais evidenciam articulações com a agenda da reforma educacional global, conforme apontado acima.

Nesse momento em que a universidade é chamada a atender demandas sanitárias ocasionadas pela pandemia, identificada como COVID-19, há o estabelecimento de uma nova racionalidade global de agir e pensar, um sistema normativo nas relações sociais que repercute para além do conhecimento técnico-científico e tecnologias nas diversas áreas do saber. As práticas pedagógicas, os saberes curriculares têm significativa importância, assim como a visão de mundo e de ciência, adquiridos ao longo das 
experiências vividas e sentidos da profissão. Ao tratar das normativas relacionadas à formação de professores, a questão do currículo emerge na medida em que seus pressupostos, organização e estrutura reverberam as intencionalidades contidas nesses documentos.

O currículo compreende um conjunto amplo de significados. Essa polissemia concernente ao campo referido é resultante de diferentes interpretações teóricas e sentidos atribuídos ao termo. O currículo pode ser pensado como campo de atividades, em que atuam múltiplos agentes e forças (GIMENO SACRISTÁN, 2000, p. 101-102), como texto em contexto e suas determinações visíveis e invisíveis (GIMENO SACRISTÁN, 2013, p.12-25), consubstanciadas no ensinar e aprender e em práticas culturais. Também pode ser considerado como um "artefato cultural", capaz de produzir identidades, que constrói sujeitos particulares, específicos (SILVA, 2003, p. 195).

Lopes e Macedo (2011) observam que o termo currículo se insere num conjunto de perspectivas e conotações, bem como no âmbito de reconfiguração de sentidos quanto ao discurso pedagógico. Consideram a organização disciplinar como uma técnica de organização e controle de saberes, sujeitos, espaços e tempos na escola e salientam que essa organização disciplinar vigora em currículos de diferentes países, configurando uma noção de currículo centrado nas disciplinas. Esta contribuição é relevante para se entender a lógica da construção dos Projetos Pedagógicos de Cursos de graduação, principalmente no âmbito do Curso de Pedagogia.

Na focalização das Diretrizes Curriculares Nacionais de Formação de professores infere-se que os modos de produção de significados do conhecimento na área originamse no quadro de contextos econômicos, políticos, sociais e culturais, com base na natureza profunda e complexa da condição humana (PACHECO, 2014, p. 389). Assim, este campo engloba intenções, reflete escolhas e expressa a influência de diversas forças sociais, econômicas e culturais, as quais são materializadas nos Projetos Pedagógicos de Cursos e nas práticas pedagógicas dos docentes.

\section{A formação inicial de professores para a educação básica: embates e tensões}

Dourado (2015) destaca que a Resolução CNE/CP n 2/2015 possui aportes e concepções fundamentais para a melhoria das dinâmicas formativas que tentam garantir um parecer de formação pautado pelo desenvolvimento de sólida formação teórica e interdisciplinar. De acordo com o relatório do Parecer CNE/CP n 2/2015, o CNE 
Base Comum Nacional ou Base Nacional Comum para formação inicial de professores da educação básica: A quem interessa a inversão de nomenclatura?

designou uma Comissão Bicameral de Formação de Professores para ficar responsável pelas normatizações da formação de profissionais do magistério da educação básica (visando ao estabelecimento de diretrizes curriculares nacionais). Após processo de ampla discussão, foi disponibilizada por esta Comissão - para audiência pública - a proposta das Diretrizes Curriculares Nacionais para a formação inicial em nível superior que se consolidou principalmente entre os anos de 2012 a 2015, a fim de se buscar organicidade nas políticas e programas.

O relatório apresenta argumentos que fundamentam teoricamente a matéria, fruto de estudos e pesquisas consolidadas, realçando que a formação de profissionais do magistério da Educação Básica tem se constituído em campo de disputas de concepções, dinâmicas, políticas, currículos, entre outros. A Resolução $\mathrm{CNE} / \mathrm{CP} \mathrm{n}^{\mathrm{o}}$ 2/2015 foi elaborada em ampla discussão com as entidades educacionais e comunidade científica, incorporando teses e princípios da formação inicial e continuada de professores (historicamente construídos), mas foi revogada pelo CNE, que instituiu duas normativas (Resolução CNE/CP n 2/2019 - diretrizes para a formação inicial de professores e criação da base nacional comum, BNC-F, e Resolução CNE/CP n ${ }^{\circ}$ 2/2020 - diretrizes para a formação continuada de professores). Evidencia-se que, no Brasil, significativa parte das IES está ainda em processos de adequação e implementação de seus cursos de licenciatura à Resolução de 2015.

Como mencionado na Introdução, optou-se por trazer algumas questões consideradas fundantes do texto referência, consubstanciado no Parecer $\mathrm{CNE} / \mathrm{CP} \mathrm{n}^{\circ}$ 22/2019, o qual deu origem à Resolução CNE/CP n n $^{\circ}$ 2019. Estas questões são explicitadas abaixo, sob a forma de ideias-chave:

a) Experiências exitosas internacionais (na perspectiva dos propositores) que podem subsidiar as Diretrizes Curriculares Nacionais para a Formação Inicial de Professores para a Educação Básica e Base Nacional Comum para a Formação Inicial de Professores da Educação Básica (BNC-Formação).

No Parecer em pauta, os Conselheiros do CNE recorrem a modelos importados, uma vez que o documento cita experiências no Chile, Austrália, dentre outros países (e não de pesquisas educacionais de instituições públicas). De acordo com Taffarel (2019) e o Boletim no 4 da ANFOPE (2019), as experiências nestes países sofreram revezes. Trazem um diagnóstico limitado da problemática educativa, visto que apresentam propostas que desconsideram as políticas educacionais instituídas, a produção e o pensamento educacional brasileiro decorrente de pesquisas e estudos realizados por 
universidades, sindicatos, instituições científicas. Além disso, perpassam visão restrita e instrumental de docência, retrocedendo nos avanços que a área alcançou com a Resolução $\mathrm{CNE} / \mathrm{CP} \mathrm{n}^{\mathrm{o}}$ 2/2015.

Nessa nova proposta há descaracterização dos núcleos formativos indicados nas Diretrizes Curriculares da Pedagogia (DCNP, Resolução CNE/CP n ${ }^{\circ}$ 1/2006): núcleo de estudos de formação geral, das áreas específicas e interdisciplinares, e do campo educacional, seus fundamentos e metodologias, e das diversas realidades educacionais; núcleo de aprofundamento e diversificação de estudos das áreas de atuação profissional, incluindo os conteúdos específicos e pedagógicos, priorizados pelo projeto pedagógico das instituições em sintonia com os sistemas de ensino; e núcleo de estudos integradores para enriquecimento curricular.

A título de exemplo, mediante um discurso gasoso, um "excesso de discursos, redundantes e repetitivos" (NÓVOA, 2009, p. 27), que promovem uma ressonância sem reflexão, o Parecer n ${ }^{\circ}$ 22/2019 cita conclusões de uma pesquisa do Instituto Canoa (o qual analisou as diretrizes nacionais de regulamentação de licenciaturas em 10 países) para justificar a importação de modelos internacionais. As principais conclusões extraídas deste trabalho foram: (a) Complementação pedagógica; (b) Duração dos cursos; (c) Critérios de ingresso nos cursos da formação inicial; (d) Currículo prático; (e) Estrutura curricular para as licenciaturas; (f) Perfil dos Egressos; (g) Agências Reguladoras; (h) Educação a Distância (EaD); (i) Avaliação (p.10-11). No entanto, essas conclusões expressam contextos e políticas diferenciadas que perpassam os vários países, distanciando-se da realidade e história da educação brasileira.

Os propositores assinalam ainda que o Programa Institucional de Bolsa de Iniciação à Docência (Pibid) é uma das experiências mais bem-sucedidas no Brasil no que concerne à formação inicial docente, tendo em vista a aproximação prática da docência com o cotidiano das escolas públicas de educação básica e com o contexto em que elas estão inseridas, assim como também argumentam que o Pibid favorece a articulação das políticas das redes de ensino, fortalecendo o regime de colaboração entre as IES formadoras e as secretarias de educação nas esferas municipais e estaduais. Ao citar apenas esta experiência, os idealizadores não levam em conta o trabalho efetuado por professores formadores e instituições, principalmente as públicas no âmbito do país.

Ainda acrescentam que "outra experiência que merece comentários é a Base Nacional Comum Curricular (BNCC)" (p.11). Em relação a este tema, tecem várias considerações, justificando a sua essencialidade. Estão ausentes neste Documento as pesquisas nesta área realizadas pelas universidades (e seus Programas de Pós-Graduação) 
Base Comum Nacional ou Base Nacional Comum para formação inicial de professores da educação básica: A quem interessa a inversão de nomenclatura?

e de entidades científicas. Quando tratam da pesquisa brasileira, há referência de apenas uma, o que indica apagamento ou invisibilidade do significativo acervo da pesquisa educacional no país.

b) Adoção da Pedagogia das Competências como referencial para a formação docente.

A economia mundial impactada pelo processo histórico do desenvolvimento do capitalismo reordena transformações no mundo do trabalho, acionadas pela mundialização do capital, gerando mudanças nas organizações e, consequentemente, no perfil do trabalhador. Assim, as relações de produção centralizadas na empregabilidade e flexibilidade dos processos dimensionam para a emergência da noção de competência e qualificação. Ramos (2001, p. 60) assinala que "confrontarmos o conceito de qualificação com a noção de competência, não implica defender uma oposição universal entre eles, mas alertar sobre uma tensão permanente que as une e as afasta dialeticamente".

Neste cenário, reverbera para a educação formar o trabalhador para atuar no mercado de trabalho globalizado, de constante alterações no âmbito das tecnologias, flexibilidade nas relações sociais e de trabalho. Além disso, a adaptação dos conceitos da teoria do capital humano para o neoliberalismo contribui para que a educação incorpore o processo econômico-produtivo em sua concepção (FRIGOTTO, 2009; SAVIANI, 2013).

Um dos aspectos decorrentes desta concepção é quando o desenvolvimento das competências fíca associado à escolaridade do indivíduo, que cada vez mais busca o ambiente escolar para se sentir incluído e capacitado para o mercado de trabalho. Nesse processo, a educação deve ser revista para atuar com um ensino flexível, que garanta maior produtividade, menor desperdício de recursos humanos e materiais e torna o trabalhador "responsável por suas capacidades como forma de alcançar a empregabilidade a partir de competências configuradas pelo mercado de trabalho" (SHIROMA; MORAES; EVANGELISTA, 2007, p.12).

De acordo com Frigotto (2009), a lógica das competências e da empregabilidade deriva da teoria do capital humano, redimensionada com base na "nova" sociabilidade capitalista. A relação do neoliberalismo com a pedagogia das competências se constitui pelo processo da empregabilidade configurado em competitividade e aspectos da pedagogia do "aprender a aprender" (SAVIANI, 2013). Nesse sentido, esta pedagogia: 
[...] apresenta-se como outra face da "pedagogia do aprender a aprender", cujo objetivo é dotar os indivíduos de comportamentos flexíveis que lhes permitam ajustar-se às condições de uma sociedade em que as próprias necessidades de sobrevivência não estão garantidas. Sua satisfação deixou de ser um compromisso coletivo, ficando sob a responsabilidade dos próprios sujeitos que, segundo a raiz etimológica dessa palavra, se encontra subjugados à "mão invisível do mercado" (SAVIANI, 2013, p. 437).

A reflexão de Saviani (2013) em torno da influência do mercado na educação corrobora com a justificativa e concepção de competência tratada no Parecer e Resolução em tela, ou seja, "no caso brasileiro, a construção de referenciais para a formação docente precisa dialogar com as dez competências gerais da BNCC, bem como com as aprendizagens essenciais que a BNCC garante aos estudantes da Educação Básica" (Parecer CNE/CP no 22/2019, p.11). A Resolução CNE/CP nº 2/2019 também destaca a questão das competências em vários artigos, como especificado abaixo:

Art. $3^{\circ}$ Com base nos mesmos princípios das competências gerais estabelecidas pela BNCC, é requerido do licenciando o desenvolvimento das correspondentes competências gerais docentes.

Parágrafo único. As competências gerais docentes, bem como as competências específicas e as habilidades correspondentes a elas, indicadas no Anexo que integra esta Resolução, compõem a BNCFormação.

Art. $4^{\circ}$ As competências específicas se referem a três dimensões fundamentais, as quais, de modo interdependente e sem hierarquia, se integram e se complementam na ação docente. São elas: I conhecimento profissional; II - prática profissional; e III - engajamento profissional.

Como afirma Saviani (2013), a "mão invisível do mercado", a responsabilização do sujeito, o ajustamento às regras da sociedade, o comportamento flexível, a rotinização e a adaptação dimensionam a formação docente, distanciando-se da concepção de professor enquanto intelectual crítico.

c) Base Nacional Comum ou Base Comum Nacional: Distanciamentos, Princípios e Abordagens.

As atuais normativas da Formação de Professores para a educação básica (Parecer CNE/CP no 22/2019 e a Resolução CNE/CP no 2/2019) traduzem uma abordagem reducionista e tecnicista da formação docente, bem como legalizam a possibilidade de que apenas 800 horas do curso sejam presenciais (para estágio e prática como componente curricular). Ou seja, 2.400 horas poderão ser ofertadas a distância. No atual momento em que estamos vivendo em decorrência da pandemia (COVID-19), a flexibilização e o 
Base Comum Nacional ou Base Nacional Comum para formação inicial de professores da educação básica: A quem interessa a inversão de nomenclatura?

ensino remoto traduzem as assimetrias que estavam postas, recrudescendo ainda mais disparidades e desigualdades neste processo formativo.

No que concerne aos termos "Base Nacional Comum" (BNC) ou "Base Comum Nacional" (BCN) para a formação de professores, pode-se até pensar que se trata de um trocadilho de nomenclatura ou de palavras que têm a mesma significação. Porém, é fundamental que se faça a devida distinção e análises tendo em vista os princípios e intencionalidades que estes termos contemplam.

As concepções da BNC-Formação Inicial se situam em um campo antagônico ao campo das que vêm sendo construídas historicamente pelo movimento dos educadores em luta pela formação, materializadas nos currículos e percursos formativos, principalmente nas universidades públicas. Ao condicionar a BNC-F a uma padronização curricular alinhada à BNCC e à formação por competências, evidenciam-se: a lógica do mercado em detrimento da lógica do direito à educação (SILVA JÚNIOR, 2015); a cultura da performatividade, ou seja, maximização do desempenho dos diferentes autores, redução dos custos operacionais, mercantilização e instrumentalização dos processos de formação inicial e continuada de professores (CANDAU, 2013); a multiplicação de sistemas de resultados, regulação supranacional, standards de formação, recentralização curricular (PACHECO, 2013, 2020); aprendizagem profissional docente (NÓVOA, 2019); e a organização curricular (GIMENO SACRISTÁN, 2013).

A BCN (ANFOPE, 2018) delineia um corpo de princípios gerais norteadores da formação docente, no contexto do movimento em defesa da formação de qualidade para os profissionais da educação, ancorada em uma proposta construída historicamente, a qual tem sido sistematicamente reiterada a cada encontro nacional da Associação, bem como pelos professores e demais atores que atuam nas universidades públicas e demais IES. Seus princípios estão especificados da seguinte forma:

$1^{\circ}$ A formação inicial, sempre presencial e em nível superior, e a continuada devem ser examinadas de forma contextualizada na sociedade brasileira ainda marcada pela permanência de desigualdades sociais;

$2^{\circ}$ A transformação do sistema educacional exige e pressupõe sua articulação com a mudança estrutural e conjuntural visando à construção de uma sociedade democrática, mais justa e igualitária;

$3^{\circ}$ a gestão democrática da educação deve ser presente na escola e demais instituições educativas, em todos os níveis, como parte integrante da democratização da sociedade brasileira;

$4^{\circ}$ a autonomia universitária como expressão da afirmação da liberdade acadêmica, científica e administrativa nos diversos espaços institucionais; 


\begin{abstract}
$5^{\circ}$ a reformulação dos cursos de formação de professores como processo constante e contínuo, próprio ao desenvolvimento dos conhecimentos científicos e tecnológicos e das demandas socioculturais;

$6^{\circ}$ a defesa da Universidade e suas Faculdades de Educação como locus prioritário para a formação dos profissionais da educação que atuam na educação básica;

$7^{\circ}$ a superação do caráter fragmentário e dicotômico da formação do pedagogo e dos demais licenciandos, que se materializa na organização curricular, reafirmando a docência como a base da identidade de todos os profissionais da educação;

$8^{\circ}$ a extinção gradativa da formação de professores em nível médio;

$9^{\circ}$ os princípios da Base Comum Nacional que dão ancoragem epistemológica e prática aos currículos de formação de professores. (ANFOPE, 2018, p. 13).
\end{abstract}

Estes fundamentos gerais ressaltam a formação inicial (sempre presencial e em nível superior) e a continuada, articulação entre os sistemas; gestão democrática; reformulação curricular; defesa da universidade pública como lócus de formação; docência como base identitária dos profissionais da educação; e incorporação dos princípios da $\mathrm{BCN}$ nos projetos pedagógicos.

Salienta-se que a concepção de BCN preconizada pela ANFOPE, desde a década de 1970, se constitui em um conjunto de eixos norteadores da organização curricular, orientadores da organização dos percursos formativos em todos os Cursos de Licenciatura - incluída a licenciatura em Pedagogia - com uma concepção sócio-histórica da formação, que deve permear e dar sustentação epistemológica aos currículos e práticas pedagógicas. São eles: sólida formação teórica e interdisciplinar; unidade teoria-prática perpassando todo o curso e não apenas a prática de ensino e os estágios supervisionados; trabalho coletivo e interdisciplinar como eixo norteador do trabalho docente; compromisso social do profissional da educação; gestão democrática entendida como manifestação do significado social das relações de poder reproduzidas no cotidiano escolar; incorporação da concepção de formação continuada visando ao aprimoramento do desempenho profissional aliado ao atendimento das demandas coletivas da escola; avaliação permanente dos cursos de formação dos profissionais da educação, como responsabilidade coletiva a ser conduzida à luz do projeto político-pedagógico de cada curso/instituição (ANFOPE, 2018, p. 14-15). Portanto, a BCN não se confunde nem com a base nacional comum da Lei de Diretrizes e Bases da Educação Nacional (Art. 64, LDBEN no 9.394/1996), e nem mesmo com a atual proposta de BNC-Formação.

No blog Formação de Professores, destinado a debater questões relativas à temática da formação docente, Helena Costa Lopes de Freitas - uma das representantes da ANFOPE - vem tecendo críticas acerca do atual Parecer (da BNC-Formação), que 
Base Comum Nacional ou Base Nacional Comum para formação inicial de professores da educação básica: A quem interessa a inversão de nomenclatura?

limita a formação docente às competências e habilidades, a qual, por sua vez, deve obedecer e estar alinhada à BNCC (um currículo nacional padronizado, de caráter obrigatório para todos os sistemas de ensino, de modo a aumentar o controle ideológico sobre o que se ensina e como se ensina). Freitas (2019) sublinha a capacidade da equipe que compõe a Comissão Bicameral de formação de professores em ignorar, secundarizar e desprezar o esforço de construção coletiva da Resolução CNE/CP no 2/2015, que ocorreu no interior do próprio CNE (durante dois anos de debates, consultas e audiências públicas - não sem dilemas e conflitos no próprio Conselho).

Pimenta, Pinto e Severo (2020) também discorrem sobre a BNC-Formação:

[...] corporifica uma tendência desintelectualizante e neotecnicista distante de uma concepção de formação pedagógica comprometida com a melhoria da qualidade social da educação. As proposições contidas nesse documento alinham-se a uma lógica formativa que simplifica os saberes e as habilidades para o exercício profissional de pedagogos(as) ao domínio de competências para o ensino e sem referências à dimensão teórico/investigativa que configura o trabalho pedagógico desenvolvido na sala de aula e em outros espaços de atuação (PIMENTA; PINTO; SEVERO, 2020, p. 12).

Fica transparente, portanto, que o conjunto atual das normativas para a formação inicial e continuada dos professores decorre de políticas sociais mais amplas, ligadas a processos e práticas de formação profissional - pautados por referentes econômicos (PACHECO, 2014) - que reverberam nos processos formativos. Estes processos devem ser objeto de discussões, análises e pesquisas dos profissionais da educação no sentido de construção de uma lógica centrada na reflexividade e no trabalho pedagógico.

\section{Considerações: a quem interessa a inversão da nomenclatura da base?}

É nesse espaço de contradição que se torna possível a resistência a respeito dos discursos velados nas normativas do CNE. Velados, porque os elaboradores das políticas de formação de professores não declaram as intenções de alinhamento com as exigências de organismos multilaterais. De acordo com Arroyo (2013, p. 30), as políticas curriculares "têm agido como um marco conformador e controlador do trabalho e das identidades profissionais". As políticas curriculares e até as suas reorientações tendem a seguir um servilismo ao movimento do mercado (ARROYO, 2013), o qual possui uma visão reducionista de formação. Segundo o autor, o currículo é o núcleo e o espaço central que estrutura o conhecimento, por isso é o território normatizado (e disputado). 
Mediante os aparatos legais, buscou-se verificar o que os referenciais teóricos apontam em relação a discursos meramente técnicos com abordagem instrumental. Assim, o que é regulado parece transgredir a autonomia das universidades públicas, as quais têm que se submeter às adequações propostas pela normativa para a organização do currículo de seus cursos de licenciatura - à luz desses documentos oficiais que têm legitimado e valorizado a divisão técnica do trabalho pedagógico, implicando sua precarização.

Com o propósito de frisar a natureza profundamente política do debate educacional bem como a natureza política do currículo, concebe-se o trabalho docente impregnado de intencionalidade, pois visa à formação humana por meio de conteúdos e habilidades de pensamento e ação, resultando em escolhas, valores, compromissos éticos (PIMENTA; LIMA, 2012).

Nesse sentido, corroborando com Pimenta e Lima (2012), Lopes (2019) argumenta acerca das implicações das legislações para a formação docente.

\begin{abstract}
A profissão professor adquire um caráter dinâmico justamente por ser concebida enquanto prática social, na qual a construção dessa identidade docente está pautada pela experiência, pelo conhecimento oriundo da formação profissional e pelos saberes pedagógicos necessários desse profissional perante sua atuação carregada de intencionalidade. Sendo assim, inquietamo-nos com os caminhos que os documentos legais têm utilizado para nortear as políticas curriculares de formação de professores, dado sua tendência de se alinharem com as exigências dos organismos multilaterais, as quais pautam-se em uma lógica mercadológica (LOPES, 2019, p. 61).
\end{abstract}

Percebe-se que a racionalidade instrumental sustenta o discurso da política educacional e curricular da atualidade e, nesse aspecto, se faz necessária a denúncia do desmonte promovido pelo $\mathrm{CNE} / \mathrm{MEC}$ no que concerne à formação e sua prescrição metodológica da atuação docente. Pimenta, Pinto e Severo (2020) assinalam que "[...] o caráter pedagógico do ensino pode ser reduzido a uma dimensão instrucional representada em métodos de transposição didática de conteúdos disciplinares” (p. 17).

À medida que os cursos de Pedagogia se afastam de um referencial amplo e crítico sobre a Didática, abre-se espaço para que propostas desintelectualizantes e instrumentalizantes do trabalho docente se consolidem, limitando a formação de professores(as) como intelectuais críticos(as) e profissionais do desenvolvimento humano à preparação para a transposição técnica de conteúdos disciplinares. Soluções dessa natureza configuram respostas neotecnicistas alinhadas às exigências do modo de produção capitalista, deslocando o sentido social da escola como espaço de construção da democratização do saber e formação 
Base Comum Nacional ou Base Nacional Comum para formação inicial de professores da educação básica: A quem interessa a inversão de nomenclatura?

cidadã para o sentido da escola como, tão somente, espaço de aquisição de competências necessárias à vida produtiva e ao disciplinamento social (p. 17).

Diante deste quadro, ao considerar-se a perspectiva de uma concepção ampliada de Educação enquanto prática construída sócio-historicamente, torna-se incompatível que se desconsidere o campo epistemológico da formação docente e os princípios preconizados por uma entidade educacional que existe e resiste desde a década de 1980, a ANFOPE. Explorar as normativas atuais do CNE em conjunto com as críticas realizadas por esta entidade nacional e de pesquisadores da área de formação de professores permite compreender as políticas materializadas na construção desses documentos.

Esta realidade coloca novos desafios, na perspectiva de se reafirmar a concepção de formação de professores construída nos últimos 40 anos pelo movimento dos educadores e defendida historicamente pela Associação em sua formulação de BCN - um conjunto de princípios orientadores dos percursos formativos de todos os professores.

No presente trabalho, entende-se que a discussão que focalize os caminhos de resistência se torna possível. Concorda-se com Freitas (2020), a qual sugere a criação de fóruns autônomos, em paralelo ao CNE, para debater a formação de professores tendo em vista que a prática pedagógica é diferente de ser professor tarefeiro, um mero executor de prescrições. Nesse sentido, o debate precisa estar, também, entre os estudantes dos cursos de licenciatura.

É com o olhar crítico que se indigna e se reage diante desta forma autoritária do CNE de instituir uma nova Resolução em que - apesar de ocorrer de modo verticalizado (com a ausência de debates em torno da elaboração das políticas) - se considera que há espaço para discussões e disputa de narrativa e conceitual, uma vez que o debate não se esgota no presente trabalho.

\section{Referências}

ANFOPE. Boletim ANFOPE n. 4, dez. 2019. Disponível em: http://www.anfope.org.br/wp-content/uploads/2019/12/BOLETIM-04-2019-ANFOPE2019-n4.pdf. Acesso em: 21 jan. 2020.

Documento final do XIX Encontro Nacional da Associação Nacional pela Formação dos Profissionais da Educação. Faculdade de Educação - UFF, 2018. 
Disponível em: http://www.anfope.org.br/wp-content/uploads/2018/11/XIX-Encontro2018.pdf. Acesso em: 28 set. 2020.

ANPED. Uma formação formatada. Posicionamento da Associação Nacional das PósGraduação e Pesquisa em Educação sobre o texto referência: Diretrizes Curriculares Nacionais e Base Nacional Comum para a formação inicial e continuada de professores da educação básica. ANPEd, 9 out. 2019. Disponível em: https://anped.org.br/sites/default/files/images/posicao_da_anped_sobre_o_texto_referen cia_diretrizes_curriculares_nacionais_e_base_nacional_comum_para_a_formacao_ini cial_e_continuada_de_professores_da_educ.pdf. Acesso em: 10 set. 2020.

ARROYO, Miguel González. Currículo, território em disputa. Petrópolis, RJ: Vozes, 2013. $375 \mathrm{p}$.

BRASIL. Ministério da educação. Conselho Nacional de Educação. Resolução $C N E / C P$ $n^{o} 1$ de 27 de outubro de 2020. Dispõe sobre as Diretrizes Curriculares Nacionais para a Formação Continuada de Professores da Educação Básica e institui a Base Nacional Comum para a Formação Continuada de Professores da Educação Básica (BNCFormação Continuada). Disponível em: http://portal.mec.gov.br/docman/outubro-2020pdf/164841-rcp001-20/file. Acesso em: 28 nov. 2020.

Ministério da educação. Conselho Nacional de Educação. Resolução $C N E / C P n^{o}$ 2 de 20 de dezembro de 2019. Define as Diretrizes Curriculares Nacionais para a Formação Inicial de Professores para a Educação Básica e institui a Base Nacional Comum para a Formação Inicial de Professores da Educação Básica (BNC-Formação). Brasília: MEC, 2019. Disponível em: http://portal.mec.gov.br/docman/dezembro-2019pdf/135951-rcp002-19/file. Acesso em: 12 fev. 2020.

Ministério da Educação. Conselho Nacional de Educação. Parecer $C N E / C P n^{o}$ 22 de 7 de novembro de 2019. Relatório das Diretrizes Curriculares Nacionais e Base Nacional Comum para a Formação Inicial e Continuada de Professores da Educação Básica. Brasília: $2019 . \quad$ MEC, Disponível em: http://portal.mec.gov.br/index.php?option=com_docman\&view=download\&alias=1247 21-texto-referencia-formacao-de-professores\&category_slug=setembro2019\&Itemid=30192/. Acesso em: 2 ago. 2020.

Ministério da Educação. Conselho Nacional de Educação. Conselho Pleno. Resolução CNE/CP $n^{o} 2$ de 1 de julho de 2015. Define as Diretrizes Curriculares Nacionais para a formação inicial em nível superior (cursos de licenciatura, cursos de formação pedagógica para graduados e cursos de segunda licenciatura) e para a formação continuada. Brasília: MEC, 2015a. Disponível em: http://portal.mec.gov.br/cne/arquivos/pdf/. Acesso em: 10 out. 2019.

Ministério da Educação. Conselho Nacional de Educação. Conselho Pleno. Parecer CNE/CP $n^{o} 2$ de 9 de junho de 2015. Diretrizes Curriculares Nacionais para a Formação Inicial e Continuada dos Profissionais do Magistério da Educação Básica. Brasília: MEC, 2015b. Disponível em: http://portal.mec.gov.br/docman/agosto-2017pdf/70431-res-cne-cp-002-03072015-pdf/file. Acesso em: 10 out. 2019. 
Base Comum Nacional ou Base Nacional Comum para formação inicial de professores da educação básica: A quem interessa a inversão de nomenclatura?

. Ministério da Educação. Conselho Nacional de Educação. Conselho Pleno. Resolução CNE/CP $n^{o} 1$ de 15 de maio de 2006. Diretrizes Curriculares Nacionais para o Curso de Pedagogia. Brasília: MEC, 2006. Disponível em: http://portal.mec.gov.br/cne/arquivos/pdf/. Acesso em: 10 out. 2019.

- Ministério da Educação. Lei de diretrizes e bases da educação nacional. Estabelece as diretrizes e bases da educação nacional. Brasília, 1996. Disponível em: http://portal.mec.gov.br/seesp/arquivos/pdf/lei9394_ldbn1.pdf. Acesso em 5 set. 2020.

Ministério da Educação. Conselho Nacional de Educação. Conselho Pleno. Resolução CNE/CP n. 1 de 2006. Diretrizes Curriculares Nacionais para o Curso de Pedagogia. Brasília: MEC, 2006. Disponível em: http://portal.mec.gov.br/cne/arquivos/pdf/. Acesso em: 10 out. 2019.

CANDAU, Vera Maria Ferrão. Currículo, Didática e formação de professores: uma teia de ideias força e perspectivas de futuro. In: OLIVEIRA, Maria Rita Neto Sales; PACHECO, José Augusto de Brito (Orgs.). Currículo, Didática e Formação de Professores. Campinas, SP: Papirus Editora, 2013. p.7-20.

CHAUÍ, Marilena. A universidade pública sob nova perspectiva. Revista Brasileira de Educação, Rio de Janeiro, n. 24, p. 5-15, set./dez. 2003.

DARDOT, Pierre; LAVAL, Christian. A nova razão do mundo: ensaio sobre a sociedade neoliberal. São Paulo: Boitempo, 2016.

DOURADO, Luiz Fernando. Diretrizes curriculares nacionais para a formação inicial e continuada dos profissionais do magistério da educação básica: concepções e desafios. Educ. Soc., v. 36, n. 131, p. 299-324, 2015. doi:10.1590/ES0101-73302015151909.

FREITAS, Helena Costa Lopes de. Lutas e desafios para a licenciatura plena em Pedagogia. YouTube. 28 set. 2020. Disponível em: https://www.youtube.com/watch?v=eCZVT-zBq8g. Acesso em: 5 out. 2020.

CNE usa referenciais docentes da Austrália para BNC da Formação. Blog da

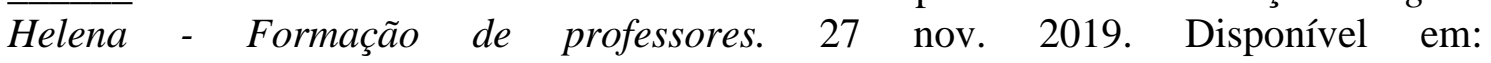
https://formacaoprofessor.com/2019/11/27/cne-usa-referenciais-docentes-da-australiapara-bnc-da-formacao/. Acesso em: $08 \mathrm{dez} .2019$

FRIGOTTO, Gaudêncio. Teoria e práxis e o antagonismo entre a formação politécnica e as relações sociais capitalistas. Trab. Educ. Saúde, Rio de Janeiro, v. 7, suplemento, p. 67-82, 2009.

GIDDENS, Anthony. Tradução de Fiker, Raul. As consequências da modernidade. São Paulo: Editora UNESP, 1991.

GIMENO SACRISTÁN, José. O currículo em ação. In: GIMENO SACRISTÁN, J. (Org.). Saberes e incertezas sobre o currículo. Porto Alegre: Penso, 2013. p. 262-280. 

. O currículo: uma reflexão sobre a prática. $3^{\text {a }}$ ed. Porto Alegre: ArtMed, 2000.

LOPES, Alice Casimiro; MACEDO, Elizabeth. Teorias de Currículo. São Paulo, Cortez, 2011.

LOPES, Yuna Lélis Beleza. Implicações das normativas do Conselho Estadual de Educação nos cursos de Pedagogia do Estado de São Paulo. 2019. 180 p. Dissertação (Mestrado em Educação - PPGEdu) - Faculdade de Filosofia, Ciências e Letras de Ribeirão Preto, Universidade de São Paulo, Ribeirão Preto (SP).

NÓVOA, António. Os Professores e a sua Formação num Tempo de Metamorfose da Escola. Educ. Real. v. 44, n. 3, Porto Alegre, 2019.

. Professores imagens do futuro presente. Lisboa: Educa, 2009. 95 p.

OLIVEIRA, Dalila Andrade. Políticas itinerantes de educação e a reestruturação da profissão docente: o papel das cúpulas da OCDE e sua recepção no contexto brasileiro. Currículo sem Fronteiras, v. 20, n. 1, p. 85-107, jan./abr. 2020.

PACHECO, José Augusto; SOUZA, Joana; MAIA, Ila Beatriz. Conhecimento e aprendizagem na educação superior: desafios curriculares e pedagógicos no século XXI. Rev. Diálogo Educ., Curitiba, v. 20, n. 65, p. 528-557, abr./jun. 2020.

PACHECO, José Augusto. Educação, Formação e Conhecimento. Portugal: Porto Editora, 2014.

PACHECO José Augusto. Políticas de formação de educadores e professores em Portugal. In: OLIVEIRA, Maria Rita Neto Sales; PACHECO, José Augusto (Orgs.). Currículo, Didática e Formação de Professores. Campinas, SP: Papirus Editora, 2013, p. 45-68.

PIMENTA, Selma Garrido; PINTO, Umberto de Andrade; SEVERO, José Leonardo Rolim de Lima. Pedagogia como lócus de formação profissional de educadores(as): desafios epistemológicos e curriculares. Práxis Educativa, Ponta Grossa, v. 15, p. 1-20, 2020. Disponível em: https://www.revistas2.uepg.br/index.php/praxiseducativa. Acesso em: 06 out. 2020.

PIMENTA, Selma Garrido; LIMA, Maria Socorro Lucena. Estágio e docência. São Paulo: Cortez, 2011. 296 p.

SHIROMA, Eneida Oto; MORAES, Maria Célia Marcondes de; EVANGELISTA, Olinda. (Org.). Política educacional. 4. ed. Rio de Janeiro: Lamparina, 2007.

SILVA JUNIOR, Celestino Alves da. Construção de um espaço público de formação. In: SILVA JUNIOR, Celestino Alves da. et al. (Orgs.). Por uma revolução no campo da formação de professores. São Paulo: Editora UNESP, 2015. p.133-148.

SILVA, Tomaz Tadeu da. Documentos de identidade: uma introdução às teorias do currículo. 2. ed. Belo Horizonte: Autêntica, 2003. 
Base Comum Nacional ou Base Nacional Comum para formação inicial de professores da educação básica: A quem interessa a inversão de nomenclatura?

SOUSA SANTOS, Boaventura. Universidade no século XXI: Para uma reforma democrática e emancipatória da Universidade. São Paulo: Cortez Editora, 2005.

TAFFAREL, Celi Nelza Zulke. Base Nacional Comum para Formação de Professores da Educação Básica (BNC-Formação): Ocultar, silenciar, inverter para o capital dominar. ANFOPE, 24 nov. 2019. Disponível em: http://www.anfope.org.br/wpcontent/uploads/2019/11/BNCF-Celi-Taffarel-24112019.pdf. Acesso em: 27 jan. 2020.

$* * *$

Recebido em: 09 dez. 2020. Aprovado em: 13 jun. 2021.

* Yuna Lélis Beleza Lopes é doutoranda no Programa de Pós-Graduação em Educação da Universidade de São Paulo, Faculdade de Filosofia Ciências e Letras de Ribeirão Preto (USP/FFCLRP). Membro do Grupo de Estudos e Pesquisas em Formação de Professores e Currículo (GEPEFOR) e afiliada à Associação Nacional pela Formação dos Profissionais da Educação (ANFOPE).

E-mail yuna.lopes@usp.br

https://orcid.org/0000-0001-6782-9751

** Noeli Prestes Padilha Rivas é Professora Associada da Universidade de São Paulo, Faculdade de Filosofia Ciências e Letras de Ribeirão Preto, Departamento de Educação, Comunicação e Informação (USP/FFCLRP/DEDIC). Atua nos cursos de graduação (Licenciaturas) e pós-graduação em Educação. Líder do Grupo de Estudos e Pesquisas sobre a Formação do Professor e Currículo- GEPEFOR/FFCLRP/USP. Pesquisa sobre formação de professores e currículo. Atualmente, é Coordenadora da Associação Nacional pela Formação dos Profissionais da Educação (ANFOPE) - São Paulo.

E-mail: noerivas@ffclrp.usp.br

https://orcid.org/0000-0002-9990-6640 